March - 2007

\title{
e-Learning in Higher Education Makes Its Debut in Cambodia: The Provincial Business Education Project
}

\author{
Buenafe R. Abdon and Seishi Ninomiya \\ University of Tsukuba, Japan \\ Robert T. Raab \\ Sustainable Development eLearning Network, USA
}

\begin{abstract}
Developing countries face a number of challenges in their efforts to compete successfully in the new global economy. Perhaps the most critical resource needed to achieve these goals is trained human capital. While many developing countries are trying to address this need through traditional means, this may not be the most effective or efficient response. e-Learning has been suggested as an alternative approach that can overcome many of the challenges involved in reaching underserved students. But most educational institutions in developing countries are unfamiliar with e-Learning, have low levels of computer availability, access, familiarity and Internet penetration which leads to skepticism about the feasibility of this approach. In an effort to assess the potential of e-Learning in meeting the needs for developing human capital in Cambodia, this paper reports on the experience and achievements of the Provincial Business Education through the Community Information Centers (CICs) project. Key findings are that eLearning was able to successfully deliver tertiary educational opportunities to underserved provincial students, Cambodian students were able to overcome serious challenges and that female Cambodian students demonstrated superior performance in online classes. These results suggest that e-Learning is an effective alternative for delivering tertiary education in Cambodia.
\end{abstract}

Keywords: e-Learning; distance learning; developing countries; Cambodia; information centers

\section{e-Learning in Higher Education Makes Its Debut in Cambodia: The Provincial Business Education Project}

The modern world is undergoing a fundamental transformation as the industrial society of the twentieth century rapidly gives way to the information society of the twenty-first century. This dynamic process promises a fundamental change in all aspects of our lives, including knowledge dissemination, social interaction, business practices, political engagement, media, education, health, leisure and entertainment (Sehrt, 2003).

Developing countries face numerous challenges as they strive to enter and successfully compete in the new global economy briefly described above. Although often blessed with the traditional 
production factors of land and labor they are generally severely constrained by inadequate levels of physical and financial capital and, perhaps most important in today's knowledge-based economies, human capital.

Human capital, the quality of labor resources which can be improved through investments, education, and training, is fast becoming the key to success for both individuals and nations. But the means to develop this critical resource are expensive and difficult to provide in developing countries where educational systems are often weak and under funded, and access to education and training, limited and inequitable.

Addressing this situation through traditional means particularly for developing countries will be costly and potentially ineffective. As the recent United Nations Educational, Scientific and Cultural Organization (UNESCO) Meta-survey on the Use of Technologies in Education (2004) concluded,

More of the same is just not going to work. Building more classrooms, and training more teachers to reach those currently unreached by education systems is unrealistic and will not be enough to meet the Education for All (EFA) challenge. Some countries are already spending considerable percentages of their Gross Domestic Product on education and have little room for maneuvering. In addition, traditional education models will no doubt be unable to achieve educational empowerment effectively in the emerging Knowledge Societies (p. 1).

Just as important is that traditional means of educational development will only bring education in developing countries up to a point already being left behind by education in the more advanced knowledge economies (Wedel, 2000).

e-Learning is increasingly being suggested as an alternative to, or a way to enhance, traditional educational approaches. e-Learning is the most recent evolution of distance learning - a learning situation where instructors and learners are separated by distance, time or both. e-Learning (sometimes also defined as 'Internet-enabled learning'), uses network technologies to create, foster, deliver, and facilitate learning, anytime and anywhere. Potential advantages of this approach for developing countries are clear. e-Learning can match the needs of non-traditional students, increase the educational facilities available to traditional students, provide cost-efficient yet effective training options, and give learners in developing nations an invaluable means of gaining a first world education tempered by third world experience.

Although e-Learning is increasingly being adopted in developed countries to reach both traditional and non-traditional students, it is still relatively unknown and unused as an educational approach in developing countries. Reasons for this are numerous. There is a general skepticism about the effectiveness of e-Learning as compared to more traditional approaches. It takes specialized skills and knowledge to develop and implement online courses that are not generally found in most developing country educational institutions. Internet connections and phone lines are unreliable. Bandwidth is narrow resulting in slow access to websites. Computers in general are not widely available and Internet connected computers even more so, particularly in areas outside of major urban centers. Traditional approaches to teaching and learning may also be a factor. In many developing countries, students are most familiar with a didactic approach and do not necessarily understand the instructor as a 'facilitator' rather than as a 'teacher' in the traditional sense. Added to these factors is the relative and absolute higher cost of Internet access in 
developing countries, most often as a result of misguided telecommunications regulations that discourage the development of Internet-access service through competition.

All of these impeding factors can certainly be found in Cambodia, one of the least developed countries in the world and now engaged in a critical effort to develop its human resources after decades of intellectual decay. In an effort to assess the potential of e-Learning as a mechanism for developing human capital in this country, a number of partners came together to implement the Provincial Business Education through the Community Information Centers project in Cambodia. This paper is a report on the activities and results of the project and an analysis of what was learned during and after project implementation.

\section{Project Background}

Cambodia is a country currently engaged in a concerted effort to overcome years of stagnation and decay as a result of political instability and war that "destroyed not only the physical infrastructure but the intellectual one as well” (Jones, n.d. ๆ 2). Probably more than any other single factor, success in this effort will depend on being able to redevelop the country's educational system. It is widely recognized that, "as this conflict-scarred, largely agricultural country in Southeast Asia tries to rebuild itself, poor education remains a critical stumbling block, slowing down labour productivity and weakening Cambodia's ability to create a sound economic base” (Chatterjee, 2006, ๆ 8).

The magnitude of this problem is severe. As Ashwill (2000) reports, the country's educational system, a cornerstone of any viable society, is in shambles. According to the United Nations, of 1,000 Cambodians born today, 290 will never go to school, 390 will repeat the first grade, and 500 will not progress beyond the primary level. Only 27 out of 1,000 who enter primary school will graduate from high school. And the situation is, if anything, more grave in terms of higher education "with just 1.2 per cent of the population enrolled, compared with an average of 20.7 per cent in all the ASEAN [Association of South East Asian Nations] countries" (Cambodia Cultural Profile, 2005, ๆ 8).

The goal of the Provincial Business Education through the Community Information Centers project was to assess the utility of e-Learning as an approach to expanding the reach of educational opportunities in higher education in support of economic and social development. The importance of higher education in the development process is now recognized. As Bloom, Canning and Chan (2006) observe, while higher education is often considered to be "an expensive and inefficient public service that largely benefited the wealthy and privileged. Now it is understood to make a necessary contribution, in concert with other factors, to the success of national efforts to boost productivity, competitiveness and economic growth” (p. 4).

A key objective of the project was to determine if eLearning could address the challenges associated with reaching students outside of Phnom Penh. These provincial students represent the vast majority of Cambodia's potential learners as less than 10 percent of Cambodians live in Phnom Penh Province (Census of Cambodia, 1998). Unfortunately, almost all opportunities for higher education are available only to those willing or able to move to the capital city and few provincial students are prepared, or can afford, to leave homes, families and jobs to move to the capital for extended periods.

The project was also interested in seeing if eLearning could work given the low level of familiarity with computers and computer technology. The vast majority of Cambodian students 
have had very limited experience with computers. Of the 698 secondary schools, only 13 percent are connected to electricity, 8 percent have generators, and 4 percent have solar panels. Seventyfive percent have no power supply at all. Very few state schools have computers. Only six percent of lower-secondary schools and 35 percent of upper-secondary schools have between one and two computers for administrative purpose. Only eight upper-secondary schools have more than 10 computers (Cambodian Ministry of Education, Youth \& Sport, n.d.). Computer availability is severely limited with 2.2 computers per 1,000 citizens, lower even than Papua New Guinea (13.7) and considerably behind the regional leader Malaysia (319.7) (Statistical Annexes, n.d.). Additionally, Internet penetration in Cambodia is extremely limited and currently estimated at only 0.3 percent of the population with most of this access is in Phnom Penh. By comparison, similar estimates of Internet penetration for the region are 9.9 percent and for the world 23.1 percent (Internet Usage in Asia, 2005).

\section{Project Partners}

This effort was part of a larger project funded by the United States Agency for International Development in Asia and the Near East (USAID/ ANE) through the dot-Gov Program and implemented by Internews Network, Inc. (www.internews.org) and The Asia Foundation (www.asiafoundation.org). A select number of Community Information Centers (CICs) (http://www.cambodiacic.org/about_project en.asp) were responsible for providing Internet access, creating an enabling learning venue for students and helping students learn the Khmer eLearning platform. The academic partner was the International Institute of Cambodia (IIC) (www.iic.edu.kh), an innovative leader in providing educational opportunities in the fields of business and Information and Communication Technologies in Cambodia. The non-profit Sustainable Development eLearning Network (SDLEARN) (www.sdlearn.net) provided on-line and face to face 'Train-the-Trainer' courses for IIC faculty and developed and provided an eLearning platform which was then configured to use Khmer Unicode. This learning management system was then installed on servers maintained and provided by the Japanese Ministry of Agriculture, Forestry and Fisheries Information Network (http://www.maffin.ad.jp/). Additional support was provided by Khmer OS (www.khmerOS.info), a local NGO responsible for training IIC instructors, CIC staff and students in the use of the Khmer Unicode keyboard.

\section{Project Development and Implementation}

The project was carried out in a phased approach with the first phase focused on establishing an implementation plan that guided the activities of all the partners. In a consultative process, the project goals, objectives and partner responsibilities were refined. Particular attention was given to the needs of the instructors chosen to design and implement the eLearning courses to be made available. SDLEARN staff provided face to face consultation and guidance on online educational pedagogical theory, online course design and best practices in eLearning technology. They also ensured that the necessary infrastructure and personnel were available for the conversion of the existing paper-based materials into digital formats and assessed the suitability of the Community Information Centers as learning venues. Details of student identification, recruitment and orientation were discussed with IIC staff and administrators. It was also during this phase that all the partners agreed to use Khmer Unicode for course content and collaboration tools such as email, online discussion boards and chat rooms.

Experience has shown that there is no better way to learn how to design and implement an online course than to actually participate in one. Therefore, as part of phase 2, SDLEARN conducted a six-week online train-the-trainer course e-Learning Course Design and Facilitation for 25 IIC 
faculty members. Participation in this course reinforced what had been covered in the face to face sessions with IIC and the hands on practice sessions gave participants exposure to SDLEARN's learning management system (LMS). The course focused on how to use the tools most commonly employed in an online learning environment, basic internet concepts, what it takes to succeed in an online course, what is expected of an online course facilitator, proven facilitation strategies, how to deal with common facilitation problems and how to design and develop an effective online course.

In addition to providing participants with the needed online teaching skills, an important outcome of this phase was the creation of a community consisting of those involved in the administration of the eLearning program and the course facilitators. This community provides an ongoing mechanism for sharing of information and a way to ask questions and receive answers and guidance from experts and peers.

Upon completion of the online course for the IIC faculty, the third phase dealt with logistical, administrative and technical details for designing and uploading the courses, promotion of the program, and recruitment of students. One hundred forty eight scholarships were awarded evenly to male and female students in five provinces: Banteay Meanchey, Kampong Cham, Kampong Som, Pailin, and Pursat. Scholarships covered tuition fees and five hours of free Internet access per week from the CICs. The three courses implemented and scholarships awarded are detailed in Table 1.

Table 1. First Round Scholarship Distribution by Course and Gender

\begin{tabular}{|l|c|c|c|}
\hline Course Title & Number of Male & Number of Female & Total \\
\hline Microeconomics & 31 & 19 & 50 \\
\hline Principles of Marketing & 23 & 27 & 50 \\
\hline Fundamental & 20 & 28 & 48 \\
\hline Accounting Principles & & & \\
\hline Total & $\mathbf{7 4}$ & $\mathbf{7 4}$ & $\mathbf{1 4 8}$ \\
\hline
\end{tabular}

Since this project was the first attempt at distance education and online learning in Cambodia, a one-day face to face orientation immediately followed selection of the scholarship recipients. This orientation was intended to introduce students to the online program, IIC, the roles and responsibilities of students, lecturers and CIC staff, and provide some technical guidance on how to sign up in the learning management system.

Upon the successful implementation of the three courses, a decision was made to offer four additional online courses, including two newly developed ones for students from Kampong Som, Kampong Cham, Pailin and Banteay Meanchey provinces. This was done to consolidate the notion of distance education in Cambodia and to capitalize on the momentum gathered from the first courses offered. To support this second round of course offerings and to build the capacity of IIC to continue to offer online courses in the future, SDLEARN conducted an additional 
eLearning Course Design and Facilitation online course for 24 IIC faculty members. The four courses subsequently implemented by IIC faculty and scholarships awarded are detailed in Table 2 .

Table 2. Second Round Scholarship Distribution by Course and Gender

\begin{tabular}{|l|c|c|c|}
\hline Course Title & Number of Male & Number of Female & Total \\
\hline Principles of Marketing & 11 & 8 & $\mathbf{1 9}$ \\
\hline Introduction to Business & 4 & 3 & 7 \\
\hline Fundamentals of Management & 31 & 24 & $\mathbf{4 7}$ \\
\hline Fundamental Accounting & 23 & & $\mathbf{4 7}$ \\
\hline Principles & & $\mathbf{5 1}$ & $\mathbf{1 2 0}$ \\
\hline Total & $\mathbf{6 9}$ & & \\
\hline
\end{tabular}

Based on experience gained during the implementation of the first round of courses, a number of adjustments were made in the way the second round was conducted. Promotional and recruitment activities were expanded and targeted at potential candidates who better fit the profile of successful students. These were identified as women, recent high school graduates and people not fully employed. The orientation program was also extended to one week to better prepare students for the online learning. Students were given a longer time to practice typing in Khmer Unicode with the Khmer keyboard and get accustomed to the LMS. Another activity added was the training of CIC staff to provide them the necessary skills and knowledge to better support the students. This was done in recognition of the important role that they played in keeping the students motivated and on-track in the online courses.

A major effort was made throughout the project to monitor, document and evaluate progress and outcomes. During the implementation of the courses, SDLEARN staff and a Khmer education consultant carefully monitored project activities and student reactions and the difficulties they encountered. IIC staff conducted regular assessments of student performance and awarded numerical grades based on assignments and examinations. Two formal evaluations of the project were also conducted by SilkRoad Cambodia (www.silkroadcambodia.com/) one at the end of Round 1 and the other at the end of the project. These evaluations involved extensive face to face and phone interviews with students and other stakeholders (Hutchinson, 2005).

\section{Results and Discussion}

Under this project, two 'semesters' of online business courses were delivered to students in five provinces. Two hundred eleven $(n=211)$ out of a starting group of 272 Cambodian students successfully completed one or more of the five online courses developed under the project. A description of these students and their performance in both Round 1 and Round 2 is provided in Table 3. 
Table 3. Characteristics and Performance of Students Who Registered for Project eLearning Courses

\begin{tabular}{|c|c|c|c|c|c|c|}
\hline Age Group & $\mathbf{F}$ & $\mathbf{M}$ & Total & $\mathbf{F}$ & $\mathbf{M}$ & Total \\
\hline$<20$ & 19 & 8 & 27 & 15 & 9 & 24 \\
\hline $21-25$ & 49 & 43 & 92 & 27 & 23 & 50 \\
\hline $26-30$ & 4 & 19 & 23 & 2 & 19 & 21 \\
\hline$>31$ & & 4 & 4 & & 10 & 10 \\
\hline Missing value & 5 & 1 & 6 & 7 & 8 & 15 \\
\hline Mean age & 22 & 24 & 23 & 22 & 26 & 24 \\
\hline Total & 77 & 75 & 152 & 51 & 69 & 120 \\
\hline Occupation & $\mathbf{F}$ & M & Total & $\mathbf{F}$ & M & Total \\
\hline Student & 44 & 28 & 72 & 32 & 25 & 57 \\
\hline Working & 28 & 46 & 74 & 19 & 44 & 63 \\
\hline Missing value & 5 & 1 & 6 & 0 & 0 & 0 \\
\hline Total & 77 & 75 & 152 & 51 & 69 & 120 \\
\hline Grade & $\mathbf{F}$ & $\mathbf{M}$ & Total & $\mathbf{F}$ & $\mathbf{M}$ & Total \\
\hline A & 13 & 3 & 16 & 13 & 15 & 28 \\
\hline B & 19 & 18 & 37 & 19 & 21 & 40 \\
\hline $\mathrm{C}$ & 18 & 9 & 27 & 8 & 16 & 24 \\
\hline D & 13 & 16 & 29 & 6 & 4 & 10 \\
\hline Fail & 4 & 9 & 13 & 5 & 13 & 18 \\
\hline Incomplete & 10 & 20 & 30 & 0 & 0 & 0 \\
\hline Total & 77 & 75 & 152 & 51 & 69 & 120 \\
\hline
\end{tabular}


Despite the disadvantages faced by these students their performance and achievements were considered to be excellent. Dropout rates were low at 20 percent in Round 1; and 0 percent in Round 2, which compares favorably with online students in more technologically advanced higher education settings in developed countries. (Carr, 2000; Dublin, 2003; Flood, 2002; Nash, 2005). More than 75 percent of these students received passing grades which was similar to other Cambodian students at IIC enrolled in traditional classroom sessions.

The views of D'Antoni's about the critical importance of the '4 A's' of e-Learning (as cited in Daniel, West, D'Antoni, \& Uvalic-Trumbic, 2005) seem to provide a basis for explaining why these students did so well. D'Antoni contends that if courses are easily accessible, the content is appropriate, participation is rewarded with formal accreditation and learning is affordable, the chances of success are significantly increased. In the case of this project, a concerted effort was made to ensure all four criteria were met.

The CICs were the main mechanism to ensure accessibility in terms of hardware, software and internet connectivity as well as in the equally important area of helping inexperienced users become familiar with the technology. They provided a comfortable learning environment that is not generally available in most provincial towns and expert technical and even pedagogical support. The importance of the contributions of the CICs and CIC staff was recognized by students who indicated that they considered CIC staff instrumental in creating a supportive learning environment. Ninety eight percent of the surveyed students rated the CICs as helpful or extremely helpful in the level of support provided and the connectivity they offered (Hutchinson, 2005).

All of the courses implemented under this project were delivered, monitored and accredited by a well respected university in Cambodia. Students who successfully completed all the course requirements and who scored sufficiently high on assignments and tests were awarded with a formal certificate from the International Institute of Cambodia and eligible for university credit toward a degree.

The course content was certainly appropriate given the needs of the country and the interests of the students in improving their career prospects. The change to a market economy since 1993 has facilitated the growth of private higher education establishments where some of the most popular courses offered are in ICT related subjects, foreign languages and business (Cambodian Ministry of Education, Youth \& Sport, n.d.). The importance of the subject matter was confirmed by alumni feedback with more than 85 percent of students indicating that they felt that their participation in an online business course had helped their job prospects (Hutchinson, 2005). That the content and interaction was all in the local language Khmer must also be recognized as a factor. The development of a Learning Management System that allowed the use of Khmer Unicode for content delivery and communication was instrumental in making this possible.

Every attempt was made to make these students' first introduction to e-Learning affordable which in Cambodia is primarily related to the prohibitively high cost of internet access. Internet access costs in Cambodia are the third highest in the Asia-Pacific region at an average of US \$85.40 per month (compare with Singapore at \$10.56). Moreover, given the disparities in wealth between countries this absolute greater price is even more of a constraint. For example, in Singapore, Internet access is equivalent to 0.5 percent of monthly GDP per capita. In Cambodia, Internet access costs almost four times the average monthly income (Nicol, 2003). In the first round, all students competed for full scholarships covered by project funds covering tuition fees and five 
hours per week of free Internet access through the CICs. In Round 2, two types of scholarships were awarded - full as well as partial scholarships which covered 50 percent of the total costs.

In addition to the general factors mentioned by D'Antoni, there were also several factors perhaps unique to Cambodia that were considered to have contributed to the success of the project. It must be recognized that, for students living outside of Phnom Penh, online courses represent the only real option for accessing accredited, higher education learning opportunities. Cambodian students in the provinces have extremely limited choice and if they cannot move to Phnom Penh for extended periods they are essentially denied access. This is even more of a problem for provincial women whose mobility is even more constrained than their male counterparts. Even from their early years, "For reasons on personal security, girls are not allowed to travel long distances and live away from family to attend upper secondary schools in provincial towns" (Ledgerwood, n.d., I 14). This situation remains even after women graduate from upper secondary school and represents a major impediment for women interested in pursuing higher education. Partly as a result of this inequity, women represent less than one third of the total population of higher education students in Cambodia (Mak, 2005). That women represented half of the participants in this project suggests that women are as interested as men in enhancing their economic futures by furthering their education. Additional evidence for the attractiveness of online learning for provincial Cambodian women can be found in their performance which was higher than that of their male classmates. A t-test on the final grades earned by all the students from the two rounds of courses showed that women's mean final grades were significantly higher than men's as measured by performance on assignments and a mid-term and final examination (see Table 4).

Table 4. Result of t-test on the Final Grades of All Students

\begin{tabular}{|l|l|l|l|l|l|l|l|}
\hline \multirow{2}{*}{ Round } & \multicolumn{5}{|c|}{ Female } & \multicolumn{3}{c|}{ Male } & \multirow{2}{*}{-value } \\
\cline { 2 - 7 } & N & Mean & SD & N & Mean & SD & \\
\hline Round 1 & 67 & 70.897 & 16.8426 & 55 & 61.3000 & 22.9257 & $-2.58436^{* *}$ \\
\hline Round 2 & 51 & 68.918 & 22.0937 & 69 & 58.3925 & 28.4163 & $-2.28195^{*}$ \\
\hline $\begin{array}{l}* \\
* * 05\end{array}<.01$ & & & & & & & \\
\hline
\end{tabular}

Survey results provided some additional reasons for the high student achievement and completion rates. These included students' appreciation of the ability to learn about and use technology and the flexibility online learning allows. In the survey of graduates, 25 percent cited the technological nature of the delivery system as one of the things they liked best about the course. Almost equally valued was that the online format allowed them to study in their own time suited to their individual schedules. Flexibility was cited as a desirable factor by 24 percent of the survey respondents. Interestingly, only seven percent of graduates indicated that they liked learning the actual course content and theory (see Figure 1). 
Figure 1. Characteristics of online courses most appreciated by students

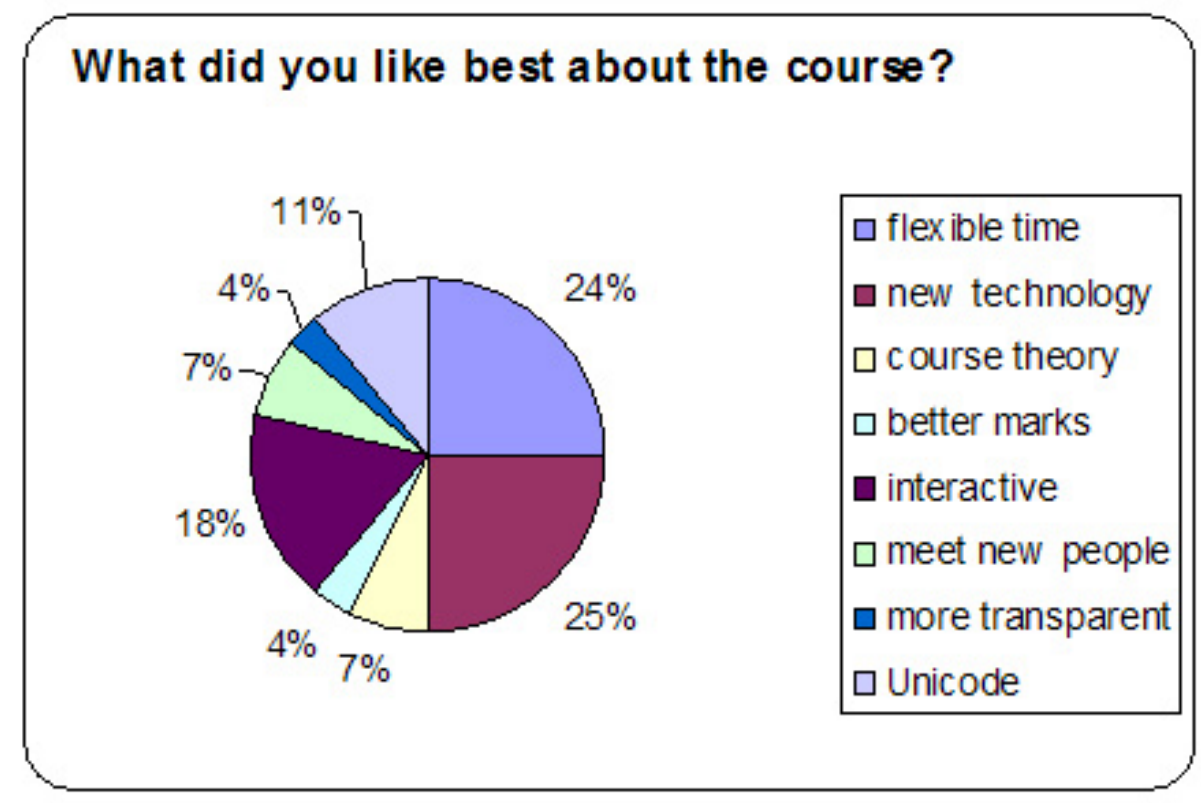

Finally, some credit has to be given to the local and international partners behind the design and implementation of the project. They demonstrated a clear understanding of individual comparative advantages, roles and responsibilities and an understanding of student needs and circumstances. They recognized the importance of close monitoring and documentation of project activities and results and were able to modify activities during implementation based on student and partner feedback. That dropout rates declined to 0 percent in Round 2 can be credited to a large degree to partners adjusting the emphasis given to student orientation before the courses started and to more comprehensive on-site support during the semester.

\section{Summary and Conclusions}

The Provincial Business Education through the Community Information Centers (CICs) project was an ambitious effort to use e-Learning to reach underserved provincial students in Cambodia with quality accredited educational opportunities in business theory and skills. Over a period of 18 months, project partners successfully delivered two 'semesters' of online business courses in Khmer language to students residing in five provinces outside Phnom Penh. Key outputs included the establishment of a distance learning program at the International Institute of Cambodia, the creation of a core group of experienced online course developers and facilitators, experienced student support personnel at the Community Information Centers, an open source Khmer language Learning Management System based on Khmer Unicode standards, and the establishment of a strong network of mutually supportive partners. Two hundred seventy two ( $n=$ 272) provincial Cambodian students took advantage of one or more of the five online courses developed under the project to improve their knowledge of key business topics and over 75 percent of these individuals scored sufficiently high on exams and assignments to receive accredited certification. These results strongly suggest that e-Learning can be a successful approach to providing quality higher education to underserved provincial students in Cambodia, and that this approach can open new opportunities for educational institutions to reach out to underserved women and men in Cambodia via online courses. 
Key factors associated with these results were that the courses met the most critical standards for success. Every attempt was made to ensure that they were easily accessible, the content was appropriate, participation was rewarded with formal accreditation and the learning was affordable.

Other contributing factors identified by students were that online learning gave added value in that eLearning allowed students to develop IT skills while also learning subject matter related business. Participation in these courses provided an opportunity to learn how to use computers and digital communication tools. This finding tends to confirm the ideas of Wedel (2000) who noted that,

A key advantage to using technology for education is that the use of technology is in itself a crucial education. Computers and the Internet are particularly suited for self-learning and for many other uses. So, for example, by learning to use the Internet to take a course in history, the student also learns language and Internet skills that will be valuable for finding international markets for local handicrafts or getting the latest crop prices on world markets (p. 2).

Given that nearly half of the students were working adults, it is not surprising that a much appreciated aspect of the courses was its flexibility in allowing learners to study at the times most convenient to their schedules. Without this flexibility, many of these students would not otherwise have been able to participate in a formal learning program.

These factors, however, are not so different from what makes e-Learning work anywhere else in the world. In the context of Cambodia, and for students living outside of Phnom Penh in particular, a major factor has to be that these courses represented the only opportunity for provincial students to further their education. That they could continue their education without leaving home seemed to be an especially attractive aspect of e-Learning for provincial women learners. While women currently represent less than one third of the total population of higher education students in Cambodia nearly 50 percent of the students who registered for and participated in the online courses were women. Women definitely demonstrated their ability to learn online and scored significantly higher on tests and assignments than their male classmates.

While there are still major difficulties to overcome and much work to be done, it is maintained that the results of this project provide strong evidence that eLearning can be a powerful approach for reaching underserved men and women learners living in the country's provinces. Perhaps the most serious impediment to more widespread adoption of eLearning will be the prohibitive cost of internet access. Survey responses showed that students would be willing to pay between US $\$ 20$ to $\$ 30$ for an accredited course and that they would be unwilling to pay extra for Internet access. Whether or not this level of effective demand will be economically attractive for educational institutions or if there are feasible options for providing affordable internet access is not yet known. There is definitely a real danger that, "Unless access can be subsidized, either by donors or the government through a universal access policy the full potential of online learning in Cambodia will remain underutilized” (Tweedie, 2006, p. 8).

It is certainly hoped that the country will overcome this and other constraints as there is strong evidence that e-Learning can and does work in Cambodia and perhaps in other countries facing similar challenges. As stated in an article published in the United Nations Chronicle: 

Abdon, Ninomiya, \& Raab

If education and capacity-building are critical steps for entering into the new global economy, e-learning should be considered a critical facet of basic development, an alternative medium of capacity-building and a means to people's empowerment (Sehrt, 2003, I 7).

\section{References}

Ashwill, M. (2000). Rebuilding a Civil Society in Cambodia: the role of education. Retrieved May 4, 2006 from: http://www.usief.org/cambodia ashwill.html

Bloom, D., Canning, D., \& Chan, K. (2006). Higher education and economic development in Africa. World Bank website. Retrieved November 13, 2006 from: http://www.worldbank.org/afr/teia/pdfs/Higher_Education_Econ_Dev.pdf

Cambodia cultural profile (2005). Cultural Profiles.org website. Retrieved May 5, 2006 from: http://www.culturalprofiles.org.uk/cambodia/Directories/Cambodia_Cultural_Profile/$\underline{36 . h t m l}$

Cambodian Ministry of Education, Youth \& Sport (n.d.). Ministry of Education, Youth \& Sport website. Retrieved November 13, 2006 from: http://www.moeys.gov.kh/en/education/ict/situation analysis.htm

Carr,S. (2000). As Distance education comes of age, the challenge is keeping the students. The Chronicle of Higher Education, 46(23), A39.

Census of Cambodia (1998). National Institute of Statistics, The Royal Government of Cambodia website. Retrieved May 5, 2006 from: http://www.nis.gov.kh/CENSUSES/Census1998/Brochure-Census98-English.PDF

Chatterjee, P. (2006). Cambodia: Learning new lessons. The Finanicial Express website. Retrieved May 5, 2006 from: http://www.financialexpressbd.com/index3.asp?cnd=3/4/2006\&section_id=16\&newsid=17579\&spcl=yes

Daniel, J., West, P., D’Antoni, S., \& Uvalic-Trumbic, S. (2005). The role of elearning in building knowledge societies in developing countries. Paper presented at the Annual Conference of the Asian Association of Open Universities, Jakarta, Indonesia, September 2005. The Commonwealth of Learning website. Retrieved May 8, 2006 from: http://www.col.org/speeches/JD_0509AAOUJakarta.htm

Dublin, L. (2003). If you look only under the street lamps...or nine e-learning myths. The eLearning Guild website. Retrieved May 8, 2006 from: http://www.eLearningguild.com/pdf/2/061603MAN.pdf

Flood, J. (2002). Read All About It: Online learning facing 80\% attrition rates. The Turkish Journal of Distance Education, 3(2). Retrieved May 10, 2006 from: http://tojde.anadolu.edu.tr/tojde6/articles/jim2.htm

Hutchinson, K. (2005). Evaluation: Provincial business education through the community information centers (CICs) project. Dot-Com Alliance website. Retrieved May 4, 2006 
from: http://www.dot-com-alliance.org/resourceptrdb/uploads/partnerfile/upload/378/eLearning_evaluation.pdf

Hutchinson, K. (2005). Evaluation: Second round of the provincial business education through the community information centers (CICs) project. Dot-Com Alliance website.

Retrieved May 4, 2006 from: http://www.dot-com-

alliance.org/resourceptrdb/uploads/partnerfile/upload/379/e-

Learning_evaluation_round_2_final.pdf

Internet Usage in Asia (2005). Internet World Stats: Usage and Population website. Retrieved May 10, 2006 from: http://www.internetworldstats.com/stats3.htm\#asia

Jones, D. (n.d.). Reasons why Pikar does not go to school. UNESCO website. Retrieved May 5, 2006 from: http://portal.unesco.org/education/en/ev.php-

URL_ID=30507\&URL_DO=DO_TOPIC\&URL_SECTION=201.html

Ledgerwood, J. (n.d.). Education in Cambodia. Northern Illinois University's Center for Southeast Asian Studies website. Retrieved May 5, 2006 from: http://www.seasite.niu.edu/khmer/Ledgerwood/education.htm

Mak, N. (2005). A current update of higher education in Southeast Asian countries: the case of Cambodia. Paper presented at the Regional Seminar on Higher Education in Southeast Asian Countries: A Current Update, Bangkok, Thailand. SEAMEO RIHED website. Retrieved May 10, 2006 from: http://www.rihed.seameo.org/Publication/HECurrentreport.pdf

Nash, R. (2005, Winter). Course Completion Rates Among Distance Learners: Identifying possible methods to improve retention. Online Journal of Distance Learning Administration, 8(4). Retrieved May 10, 2006 from: http://www.westga.edu/ distance/ojdla/winter84/nash84.htm

Nicol, C. (2003). ICT Policy: A Beginner’s Handbook. The Association for Progressive Communications website. Retrieved November 13, 2006 from: http://rights.apc.org/handbook/ICT_06.shtml

Statistical Annexes (n.d.). UNDP Regional Centre in Colombo website. Retrieved November 13, 2006 from: http://www.undprcc.lk/rdhr2006/G2235H835352H/P24314143234344343242_PDF_21 $\underline{4335 / \text { Statistical\%20Annexures.pdf }}$

Sehrt, M. (2003). e-Learning in the Developing Countries: Digital divide into digital opportunities. UN Chronicle, XL(4). Retrieved May 8, 2006 from: http://www.un.org/Pubs/chronicle/2003/issue4/0403p45.asp

Tweedie, P. (2006). Provincial business education through the community information centers. Phnom Penh, Cambodia

Wedel, P. (2000). Distributed education as a pathway to a knowledge economy in the Greater Mekong Subregion. Kenan Institute Asia website. Retrieved May 8, 2006 from: http://www.kiasia.org/download/hrd.htm 
UNESCO (2004). Metasurvey on the use of technologies in education in Asia and the Pacific on the UNESCO website. Retrieved May 8, 2006 from:

http://www.unescobkk.org/fileadmin/user_upload/ict/Metasurvey/introduction.pdf

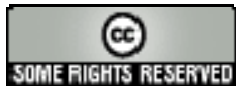

